\title{
Da politica em contextos de interconhecimento
}

VOMMARO, Gabriel; COMBES, Hélène. El clientelismo político: desde 1950 hasta nuestros días. Buenos Aires: Siglo XXI Editores, 2016, 192 p.

\section{Juliane Sant'Ana Bento*}

\section{Resumo}

A obra resenhada apresenta um panorama didático e imprescindível dos estudos sobre o clientelismo, inclusive em sociedades contemporâneas. Representa uma contribuição fundamental para as ciências sociais, ao ampliar a perspectiva da denunciação, ressaltar que o clientelismo é noção dificilmente dissociada de uma intenção moral e, especialmente, indagar em que medida os diagnósticos intelectuais da patologia da política são mobilizados na condição de crítica, deslegitimação ou desqualificação das práticas dos oponentes na luta política.

Palavras-chave: Ciência Política, Patronagem, Trocas interpessoais, Vote buying, Economia Moral.

*Universidade Federal do Rio Grande do Sul, Porto Alegre, RS, Brasil 


\section{On politics in inter-knowledge contexts}

\section{Abstract}

The book reviewed presents an essential and very didactic panorama of studies on clientelism, including on contemporary societies. It represents a fundamental contribution to the social sciences by broadening the perspective of denunciation, emphasizing that clientelism is a concept that is difficult to dissociate from a moral intention, and, especially, inquiring to what extent the intellectual diagnoses of that pathology of politics are mobilized as criticism, delegitimization or disqualification of the practices of opponents involved in the political struggle.

Keywords: Political science, Interpersonal exchanges, Political patronage, Vote buying. Moral economy.

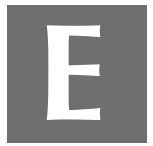

$\mathrm{m}$ que pese o formato conciso, que inevitavelmente limita o aprofundamento em pontos que o mereceriam, e apesar da ausência de menção aos casos e estudos brasileiros sobre o tema, El clientelismo político é obra singular a ser incorporada ao repertório bibliográfico das ciências sociais no Brasil. Publicada na América Latina pela Siglo XXI, após o sucesso da primeira versão francesa, lançada sob o título Sociologie du clientélisme, em outubro de 2015, na coleção Repères da editora La Découverte, o livro mantém a vocação "sintética, panorâmica e didática" (Grill, 2014) do selo parisiense.

Hélène Combes, pesquisadora do Centre national de la recherche scientifique da França e professora do Centro de Pesquisas Internacionais da Science Po, assina a obra em parceria com Gabriel Vommaro, pesquisador do Consejo Nacional de Investigaciones Científicas y Técnicas da Argentina e professor da Universidade Nacional de General Sarmiento. Ambos são herdeiros da tradição sociológica francesa predominante nos últimos quarenta anos, da qual uma das principais matrizes analíticas origina-se dos trabalhos de Pierre Bourdieu, na sequência de quem, um conjunto de pesquisadores envolvidos com objetos eminentemente políticos, a exemplo de Alain Garrigou e Michel Offerlé, vem a consolidar-se. 
No mínimo, dois argumentos centrais do texto justificam a conveniência de sua pronta assimilação pelas ciências sociais brasileiras: a constatação da recorrência do clientelismo nas práticas políticas contemporâneas e seu uso enquanto instrumento de crítica e deslegitimação na luta política. Primeiramente, a constatação, apoiada em farto material empírico, de que o clientelismo coexiste com ambientes de consolidadas instituições formais, ou seja, com sociedades democraticamente desenvolvidas, contribui particularmente à conjuntura política e científica nacional. Embora a crença coletiva - científica, inclusive - no modelo weberiano de que o Estado racional-legal é universal, anônimo, e seria a solução ao atraso das relações políticas tradicionais regidas por obrigações e reciprocidade, tenha pautado a maioria dos estudos sobre o tema, impõe-se desafiá-la, quando Combes e Vommaro demonstram que é da essência do métier político dos eleitos o domínio da lógica personalista e o trabalho de proximidade com os eleitores.

Em segundo lugar, os autores definem "clientelismo" para além da concepção clássica: poderia meramente tratar-se de uma relação política personalizada entre atores dotados de recursos desiguais, na qual ocorrem trocas de bens, geralmente públicos. Mais do que isso, entendem que o vínculo é regulado por princípios morais mobilizados de modo contraditório pelos atores engajados nessa relação e por aqueles exteriores a ela, que a denunciam como desviante ou patológica. Eis a importância da obra para as ciências sociais: ampliar a perspectiva da denunciação, ressaltar que o clientelismo é noção dificilmente dissociada de uma intenção moral e, especialmente, indagar em que medida os diagnósticos intelectuais da patologia da política são mobilizados na condição de crítica, deslegitimação ou desqualificação das práticas dos oponentes na luta política.

Com o intuito de analisar criticamente a construção social e histórica das categorias, Combes e Vommaro dissuadem o leitor de permanecer no jogo das tipologias, do excessivo nominalismo e das grandes variáveis explicativas. Ao invés disso, defendem um exercício fundamental para desnaturalizar o clientelismo: este será melhor observado, se atentarmos à política concreta, à descrição dos casos e das práticas dos atores. 
Dividida em seis capítulos, a obra inicia dedicando-se a apresentar a gênese e a evolução do tratamento científico sobre o clientelismo. Por meio de história intelectual do conceito, os autores apresentam os primeiros estudos sobre relações pessoais em sociedades tradicionais, seguidos das posteriores análises sobre as sociedades mediterrâneas para, enfim, abordar a apropriação do clientelismo pela Ciência Política nos recentes trabalhos sobre vote buying. No segundo capítulo destinado aos atores da relação clientelista, ponderam as características das categorias de "máquinas políticas", "patrões", "intermediários" e "clientes", para sugerir maior atenção aos últimos, frequentemente negligenciados. Em virtude da relevância dos contextos nacionais, mas também motivadas pelas afiliações profissionais dos autores, as duas seções seguintes abordam, cada uma, dois estudos de caso a partir das perspectivas europeia (Itália e França) e latino-americana (Argentina e México). O uso do clientelismo como um "problema" redescoberto no espaço internacional é o objeto da quinta parte. Por fim, os autores sublinham relevantes questões teóricas e metodológicas ainda por serem enfrentadas pelos estudos que objetivem compreender o trabalho político em situações de interconhecimento.

No primeiro capítulo, fazem competente revisão dos estudos etnográficos que no pós Segunda Guerra buscaram conhecer de que forma os vínculos de parentela e de amizade compunham parte significativa da vida política, principalmente no nível local e inclusive em sociedades modernas. Citam Wolf (1966) e suas duas inovações centrais, a primeira sobre a importância dos vínculos entre o local e o nacional para entender as funções das instituições e das práticas políticas e econômicas, e a segunda sobre a capacidade que as estruturas informais têm de agir paralelamente às formais. Wolf demonstrara que, na ausência do poder central, por meio de instituições formais, obrigações coletivas informais se impunham sob a forma de alianças de amizade ou compadrio.

Referem também Foster (1963), que viu nas relações de vínculos assimétricos do mundo rural no México a estabilidade daquele sistema social, na medida em que garantiam o acesso aos bens desigualmente 
distribuídos. Foster contribui para a distinção entre o discurso ideal da representação pelo grupo, e o efetivo comportamento na relação patrãocliente. A distância entre o relato dos atores e a relação de força real nunca pôde ser desconsiderada a partir de então. Já o trabalho de Pitt-Rivers (1954), na Espanha, permite observar que a comunidade é um conjunto de relações interpessoais moldadas por valores como honra, vergonha, amizade e respeito. Desse modo, mais do que a mera troca de dons e contradons, por definição assimétrica, as relações políticas personalizadas importavam uma simetria das prestações imateriais, uma vez que os princípios morais vigentes junto à comunidade faziam ambos os atores, patrão e cliente, ganharem com o aumento de seu prestígio. Mereceu menção, ainda, a contribuição de Bailey (1971) sobre o engajamento de clientela através das máquinas políticas locais na Índia. Pela primeira vez, o interesse/desinteresse do cliente foi considerado numa relação de clientela, distinguindo-se entre os noyau, vinculados por engajamento moral, leais ao patrão, porque têm seu destino atrelado ao deste; da entourage, clientes de segunda ordem, ligados por engajamento instrumental, mediante estratégia calculada, e suscetíveis de afastamento provocado por oferta mais benéfica de outro patrão.

Principalmente a partir da contribuição dos referidos autores, a noção de clientelismo é associada, no seu surgimento, à antropologia social, que se detinha no estudo de comunidades rurais do mundo mediterrâneo: segundo Combes (2011), os antropólogos descreviam as relações de poder em sociedades tradicionais submetidas à penetração do Estado. A apropriação do clientelismo pela Ciência Política substituiu o foco, passando das relações interpessoais à abordagem estrutural-funcionalista, a fim de apreender as relações entre grupos e organizações e a manutenção de regimes políticos. Uma nomenclatura dos sistemas clientelares é desenvolvida: feudal, patrimonial (tradicional ou moderno) e industrial, e estes passam a ser entendidos como causa e consequência do subdesenvolvimento - sistemas em que patrões controlam recursos vitais e têm interesse na manutenção do status quo. No entanto, o ethos clientelista se manifestaria também em sociedades plenamente desenvolvidas, em que há presença 
de grupos "culturalmente inclinados" à busca de atalhos como estratégia individual ou familiar para as trocas políticas. De acordo com a Ciência Política dominante, este modelo acarreta obstáculos ao desenvolvimento político e outras patologias mais severas, como a corrupção.

No capítulo 2, sobre os atores do clientelismo, Combes e Vommaro sublinham as máquinas políticas, como as organizações de convivialidade que reproduzem elites locais. Através delas, são fidelizados os clientes, por meio de redistribuição de incitações materiais, os quais virão a ser mobilizados em períodos eleitorais. O patrão, ator clássico nos estudos de caso norte-americano, é favorecido pela ausência de administração profissional, quando pode distribuir empregos públicos em troca de apoio político. O intermediário, ator responsável pela mobilização das bases, é figura central desse círculo de sociabilidade tradicional: domina códigos simbólicos, de modo a saber demonstrar sua habilidade em mediar e conciliar reivindicações locais particularistas e a redistribuição dos serviços públicos fornecidos pelas instituições centrais. O cliente, por muito tempo observado como "dominado" sob o olhar miserabilista da política em meios populares, hoje é observado menos em razão dos efeitos da relação clientelar, do que pelas maneiras como essa relação é percebida e forjada por seus protagonistas. Atenta-se, portanto, muito mais à dimensão simbólica das trocas e aos julgamentos morais que conferem os princípios de percepção e de apreciação do mundo social dos atores que participam dessas relações políticas: ou seja, aos conjuntos de ações, avaliações e crenças que permitem entender como as instituições são mobilizadas pelos cidadãos. Em geral, clientes se autodefinem como reconhecedores e colaboradores de dirigentes que prestam "ajudas". Compreender o ponto de vista do cliente e ultrapassar a "visão miserabilista" exige restituir o conjunto do tecido social do bairro e suas relações com o exterior, de modo a entender como se articulam avaliações morais, internas e externas, do legítimo e do ilegítimo na política. Para Combes e Vommaro, denunciar como "clientelistas" certas práticas é o papel desempenhado pela classe média, portadora de princípios 
morais mobilizados contra as práticas "desviantes", que participa da relação clientelar, assim, na função de codificadora moral e jurídica.

A fim de empreender perspectiva comparada, os autores iniciam a análise pelo estudo de casos europeus. No capítulo 3, abordam a Itália, onde as condições de construção do Estado unificado são os fatores principais para a difusão do clientelismo. A aliança por intermédio de redes e interesses particularistas entre elites heterogêneas (burguesia industrial do norte e aristocracia agrária do sul) fez consolidar como vínculo político dominante as lógicas de patronagem e clientela. Lógicas familiares ligadas à busca de proveito imediato são características da relação pragmática e instrumental com as instituições. Mesmo quando ocorre a substituição dessas elites por um novo pessoal político, a explicação dominante para a realidade italiana permanece sendo a da anomalia causada por uma cultura política atrasada e paroquial, centrada nos interesses locais e nas disputas de facções. Entretanto, os autores apresentam trabalhos que questionam esse juízo de anormalidade, por entenderem que a história italiana é vista sob olhar que a distancia das democracias desenvolvidas. Há os intérpretes que veem nessas redes locais de clientela o elemento estruturante e favorecedor do desenvolvimento econômico, uma vez que possibilitam a instalação de novas instituições estatais e, logo, o acesso mais universalista a bens e serviços.

Já no caso francês, a discussão sobre clientelismo não se estrutura nacionalmente. É restrita à Córsega e ao momento histórico de ampliação do mercado político com a adoção do sufrágio universal. Naquela ilha, o clientelismo é elemento da evolução do fenômeno notabiliário: se a integração a grupos familiares ou redes de solidariedade passou a ser pensada em termos partidários, as oposições políticas mantêm a estrutura clânica e a reprodução dos notáveis. Transformações sociais levaram à deslegitimação do sistema clânico, forçando os notáveis a se adaptarem à contestação. Desse modo, os próprios notáveis adotaram comportamentos inovadores e participaram de empresas de modernização estatal.

Quanto ao mercado político francês do séc. XIX, se, no começo, a democracia representativa operava ratificando a autoridade social evidente 
dos notáveis, o hábito das competições eleitorais engendrou a desqualificação das relações notabiliares. No entanto, a mobilização eleitoral levou a novas formas de relações de clientela - única forma de combater com igualdade de armas o poder dos notáveis - e também à substituição da oferta de bens privados pela oferta de bens públicos indivisíveis e abstratos, tais como um discurso, a representação e imagens de futuro.

O quarto capítulo, Combes e Vommaro dedicam à América Latina, região em que as instituições políticas democráticas foram desenvolvidas quase ao mesmo tempo que na Europa, porém sobre relações sociais consideradas como arcaicas. Apontam como predominavam leituras próximas às usadas para o mundo mediterrâneo, centradas nas "anomalias", para entender o "coronelismo" brasileiro ou o clientelismo colombiano, mexicano ou argentino. A herança colonial explicava a importância dos vínculos personalizados, das instituições informais e do monopólio das burocracias estatais por oligarquias, mas a modernização política deu-se pelo aparecimento de forças políticas "populistas" pouco compatíveis com ideais das democracias liberais ocidentais.

O caso argentino, de mais um Estado latino-americano fundado por acordo entre elites, caracteriza-se pela dificuldade em criar uma ordem política durável. As classes populares tendem a ser mobilizadas para apoiar elites em conflito, de modo que a participação política é controlada por estas. A mobilização das redes de clientela é feita por "líderes naturais" forjados dentro das hierarquias institucionais, o que torna empregos públicos uma fonte de construção de lealdades políticas (militares, policiais, guarda nacionais, posteriormente também funcionários municipais, juízes de paz, etc.). Um savoir-faire relacional e um conhecimento das parentelas faz com que as eleições sejam um "negócio de elites locais", em que as fraudes e o recurso à violência explicam a fraca e controlada participação.

Com a chegada dos radicais ao governo argentino, em 1916, houve a modernização das redes de clientela. A ampliação das práticas de patronagem deu acesso ao emprego público a novos grupos, o que, somado à distribuição de bens, manteve a construção de lealdades. A 
decepção das elites tradicionais com a democracia eleitoral é refletida no golpe de 1930, em que a queda de Yrigoyen é marcada pela ascensão conservadora e justificada pela moralização da política. Ainda que os radicais permanecessem a maioria silenciosa e desarticulada, uma estratégia de mobilização conservadora dos cidadãos provocou a adesão massiva ao partido e fez surgir um conservadorismo popular.

A renovação da sociedade civil, em 1945, pelo peronismo, resulta da mobilização social da classe trabalhadora pouco politizada, através dos sindicatos e da fundação Eva Peron. A modernização da assistência promovida por esta última, antes reservada às mulheres da elite política e social, foi a "mão clientelar" do populismo peronista, vigente até os anos 1980, quando o processo de dessindicalização diminui o poder da estrutura partidária. Ao peronismo, portanto, atribui-se a redefinição dos vínculos com o mundo popular, eis que tornou central a figura do dirigente territorial como um mediador para uma rede de resolução de problemas.

A respeito do México, Combes e Vommaro reportam que as primeiras eleições sob o império espanhol, de 1812, nas quais já vigiam a cidadania e o direito de voto dos indígenas, foram pautadas por listas eleitorais étnicas: resultaram sem nenhum espanhol eleito. Desde então, o léxico sobre eleições é forjado por corrupção, manipulação, suspeita, suborno, etc. Na primeira lei eleitoral após a revolução de 1910, rejeitou-se o voto indireto e estabeleceu-se como valores o universalismo e a confidencialidade do voto, a eficácia da apuração e a confiabilidade do escrutínio. Mesmo mecanismos inclusivos, como o uso de discos de cores para o voto dos analfabetos, foram adotados. Deste período data a institucionalização do regime de partido dominante, no qual o Partido Revolucionário Institucional (PRI) concentrava os vínculos de mediação por meio de vasto aparelho partidário e estatal. Inicialmente, o poder local era resistente às regulações, porque os caciques detinham um poder pessoal, informal e de reciprocidade. $\grave{A}$ época da revolução, impediam que o Estado penetrasse nas zonas rurais; a partir de 1940, no entanto, foram o meio pelo qual o governo aprofundou localmente seu poder. As comunidades indígenas, privilegiadas pela reforma 
agrária que pôs fim à quase servidão nas fazendas de milho, cana e café, viram surgir novos dirigentes entre seus membros, elevados à condição de intermediários incontornáveis pelo monopólio da produção lucrativa de álcool.

Nas cidades, o controle da população mexicana era feito por políticas públicas locais. O apoio urbano ao PRI ocorria pela incorporação clientelista dos mais pobres ao jogo político através da distribuição de bens e serviços: a negociação de financiamentos, a regularização de títulos de propriedade, a garantia de acesso à água e luz, por exemplo, eram procedimentos praticados nas organizações de bairro controladas pelos caciques. Esta política urbana também é forma de politização dos meios populares: o fim da coerção do autoritarismo clientelista permitiu uma transição para a cidadania, ou um "semi-clientelismo". Na década de 1990, a narrativa da suspeita de fraude é deslocada para a denúncia da compra de votos. As reformas econômicas do período limitaram os recursos a serem redistribuídos pelo Estado e, consequentemente, programas compensatórios passaram a ser objeto de competição política. Partidos de oposição passaram a denunciar que municípios controlados pelo PRI recebiam mais alocações do que municípios com maior pluralismo político. Entretanto, se o clientelismo era método de atuação do PRI, também passou a ser dos partidos que o sucederam.

Outro elemento que Combes e Vommaro sublinham é o fato de que o clientelismo é denunciado por certo uso político que faria da administração pública, eximindo de questionar a transparência do processo eleitoral, mas criticando a mobilização política das classes populares por partidos ditos populistas. Referem-se à lenda da democracia representativa nascida, no século XIX, da manipulação das classes populares pelas elites. Ilustra essa constatação a reforma eleitoral mexicana de 2008 que sucedeu a crise das eleições de 2006: a proibição de campanhas na TV e o financiamento público das campanhas teve por efeito a renovação da presença territorial dos partidos e a valorização do conhecimento dos modos de fazer denúncia. A distribuição entre militantes de um cartão para compras em um supermercado acabou vindo a ser negada pela justiça mexicana como 
configuradora de compra de voto, em que pese a mobilização partidária tenha passado a ser fortemente apresentada sob tal viés criminal: uma recodificação local do novo esquema de entendimento sobre vote buying difundido em escala continental.

Na quinta seção, sobre o espaço internacional de governança e a redescoberta do "problema" clientelar, Combes e Vommaro tratam das organizações multilaterais de crédito e instituições internacionais que definem políticas públicas em países emergentes. Elas emitem títulos de "governo transparente", de "administração de qualidade" e credenciam aliados locais, como ONGs e think tanks nacionais, beneficiados pelo prestígio desses agentes internacionais. Os autores definem-nas como "empresas de exportação da democracia liberal ocidental" e atribuem a elas a promoção de programas de luta contra a pobreza, nos quais a questão do clientelismo é central. Mal a ser combatido, ele é obstáculo ao reforço das capacidades das classes menos favorecidas para que sejam protagonistas de sua luta. Por isso, a maior seletividade na escolha dos beneficiários é critério que evitaria a manipulação dos mesmos pelas clientelas políticas: a "luta contra o clientelismo" é favorecida na agenda midiática e política, associando as políticas sociais e o uso de bens públicos com fins políticos economicamente ineficazes e moralmente corruptos.

A "qualidade da democracia" é citada como um dispositivo por vezes técnico, político e moral capaz de fazer convergir a energia dos agentes para a defesa do "bem moral" que seria tal regime institucional. Este rótulo permitiria a definição mínima e consensual da democracia compatível com a ideologia dominante e autorizaria juristas e cientistas políticos à condição de especialistas destacados para lidar com os alvos prioritários das práticas corrompidas. O clientelismo visto como subespécie de práticas corrompidas é o modo como instituições como a Transparência Internacional adaptam sua definição para torná-la compatível com a missão de luta contra a corrupção. Assim, o mercado intelectual dos empreendedores morais em guerra contra o clientelismo opera em dois momentos: primeiro, definindo a relação de clientela para identificar as trocas sociais propriamente 
patológicas; e depois, usando um instrumento para medir a intensidade dessa troca em termos estatísticos, fornecendo argumentos de valores, estratégia fundamental na construção dos problemas públicos. Decorre de uma concepção instrumentalista de ciência política que substitui a análise das clientelas por estudos economicistas sobre vote buying, reduzindo a relação de troca ao cálculo de custo-benefício, em que dons e contra dons são substituídos pela perspectiva da remuneração do voto.

A compra de votos deixa de ser parte de relação complexa e durável para ser troca mercantil e pontual, deixa de ser troca política e passa a ser redução economicista limitada a sua importância quantitativa. Os vínculos de interconhecimento e as avaliações morais em jogo entre os agentes restam ignorados em detrimento da dimensão utilitarista das eleições, retratando um fenômeno geral das ciências sociais na década de 1990, o triunfo do Homo economicus. Sendo compreendida como puramente episódica, a compra de voto pode ser evitada pelo monitoramento do corruptor e pela supervisão do pacto estabelecido com o eleitor: assim, o trabalho político dos partidos de mobilização eleitoral é sistematicamente colocado sob suspeita. A melhoria das práticas eleitorais é missão que reúne os especialistas em uma rede e favorece a cooperação internacional com vistas a recomendar reformas eleitorais que otimizem a tecnologia do voto. Referindo-se à ideia de Bruno Latour, de que o problema público do clientelismo é caixa-preta que engloba uma série de projetos morais antes dispersos em diferentes etiquetas (fraudes eleitorais, corrupção, má governança, ineficácia dos serviços públicos), Combes e Vommaro identificam nele uma nova categoria de definição de problema em países emergentes. Através dela, o trabalho político do Estado é recodificado e a intervenção dos especialistas para o monitoramento das eleições e a criação de instituições de controle se fortalece.

Com o propósito de fornecer pistas para futuras pesquisas, os autores dedicam-se, no capítulo sexto, denominado trabalho político e sentido moral em contextos de interconhecimento, a partir do conceito de economia moral, a refletir sobre o tempo longo das trocas que criam obrigações de 
tipo moral. A noção possibilita identificar como se organizam os princípios de percepção e os sentidos de justiça envolvidos, detalhando os vínculo personalistas para além de um conceito tão abrangente que dificulta o entendimento. Repensar os termos da troca implica admiti-la como uma regulação não mercantil, em que normas e obrigações sociais têm funções apropriadas pelas diversas partes da sociedade. Além disso, permite superar uma visão conservadora da história, de que os comportamentos políticos das classes populares são sempre, necessariamente, prejudicados por irracionalidade. A ideia de economia moral, tomada no sentido original da economia - de uma organização em que cada parte é ligada ao conjunto e dispõe de função e obrigação - permite dar conta da organização moral das relações políticas, em que os vínculos são pautados e avaliados por noções partilhadas de justiça. Então, patrão e cliente, dirigente e dirigido, são partes de uma mesma configuração normativa.

Defendem os autores, contra percepções de que o conceito foi invalidado pela dominação capitalista e não vige mais na configuração política contemporânea, que a economia moral é plenamente funcional, porque regula localmente o mérito e o direito de acesso aos bens em configurações nas quais relações personalizadas moldam o funcionamento da política. A vantagem da adoção do termo seria apreender a dominação, sem prejulgar a interiorização incondicional do consentimento, uma vez que participar de uma economia moral não significa renunciar ao conflito. A tensão é parte da definição e redefinição do sentido de justiça que anima as trocas, cuja restituição das formas justas e legítimas, por si só, é o cerne das análises de política face a face. Ademais, não se trocam apenas bens materiais, mas também sentimentos e valores, como reconhecimento, deferência e gratidão. As avaliações morais importam, porque ajudas públicas não são monopólio e a multiplicação dos intermediários em conjunturas pluralistas permite aos clientes desertarem ou promoverem ajustes morais a fim de negociar os termos e equivalências nas trocas.

Apreender a natureza da troca e seu valor moral só é possível, se observado o momento da interação. Assim como o pesquisador não pode se 
contentar com as denúncias de clientelismo por alguns agentes, do mesmo modo não pode tomar como prova do clientelismo as representações que os intermediários dão de si. Combes e Vommaro dão o exemplo do trabalho que fizeram junto a um líder local mexicano, que transportava pessoas gratuitamente, distribuía panfletos, tentava convencer da plataforma de um candidato. Importa observar o que está em jogo na interação, como ele sai de situações incômodas protegendo seu valor social de quem "ajuda as pessoas", mesmo que isso lhe traga constrangimentos e obrigações, e como importa se atribuir o mérito de uma demanda conquistada.

O principal desafio metodológico que destacam para o estudo das trocas na política é a restituição, no contexto de sua posição social e militante, além do posicionamento nas configurações políticas locais: a análise das propriedades sociais dos agentes é essencial para compreender o que está em jogo na relação de dominação. O discurso dos clientes, por exemplo, raras vezes é objetivado em suas posições: a possibilidade de escolher ofertas de patronagem permite nuançar o lugar da dominação. Já as elites, dirigentes e eleitos também mobilizam julgamentos morais que organizam suas práticas e precisam ser compreendidos para que se evite o relato heroico de seus papéis. Por tudo isso, as trocas políticas desiguais são tidas como fatos sociais totais e sua abordagem em termos de economia moral permite ver a complexidade e a articulação com normas de justiça específicas, mobilizadas em função de contextos e redefinidas ao longo do tempo.

Tal como Auyero (2001) e Quiróz (2011), o que Combes e Vommaro nos oferecem é a convicção de que o ponto de vista dos clientes precisa ser levado em consideração, se pretendermos efetivamente considerar a complexidade e as controvérsias das relações políticas em contextos de interconhecimento. A simples denúncia do clientelismo, conforme discute Auyero, geralmente é mobilizada por atores externos à relação, os quais costumam tirar proveito dessa denúncia na luta política. Buscar as lógicas e as razões populares desses intercâmbios políticos e o modo como avaliam positivamente e legitimam tais relações permite dar conta da economia 
moral que opera nessas trocas políticas, ainda que não consintam com a dominação que sofrem.

Juliane Sant'Ana Bento é Doutora em Ciência Política (UFRGS), pesquisadora do Núcleo de Estudos em Justiça e Poder Político do Programa de Pós-Graduação em Ciência Política da UFRGS e Professora temporária no Departamento de Direito Público e Filosofia do Direito da Universidade Federal do Rio Grande do Sul.

$\risingdotseq$ julianebento@ymail.com

\section{Referências}

1. AUYERO, Javier. La política de los pobres: las prácticas del clientelismo del Peronismo. Buenos Aires: Manantial, 2001.

2. BAILEY, Frederick G. Les règles du jeu politique. Paris: PUF, 1971.

3. COMBES, Hélène. ¿Dónde estamos con el estudio del clientelismo? Desacatos

- Revista de Ciências Sociais, n. 36, p. 13-32, 2011.

4. COMBES, Hélène; VOMMARO, Gabriel. Sociologie du clientélisme. Paris: La Découverte, 2015.

5. FOSTER, George M. The dyadic contract in Tzintzuntzan: patron-client relationship. American Anthropologist, v. 65, n. 6, p. 1280-1294, 1963.

6. GRILL, Igor G. Efeitos da "redescoberta das instituições" na sociologia política francesa. Política e Sociedade, v. 13, n. 27, p. 237-242, 2014.

7. PITT-RIVERS, Julian A. The people of the Sierra. Londres: Weidenfeld and Nicholson, 1954.

8. QUIRÓZ, Julieta. El porqué de los que van: peronistas y piqueteros en el Gran Buenos Aires (una antropología de la política vivida). Buenos Aires: Antropofagia, 2011.

9. WOLF, Eric R. Kinship, friendship, and patron-client relations in complex societies. In: BANTON, Michael. (Org.) The Social anthropology of complex societies. Londres: Tavistock, 1966.

10. VOMMARO, Gabriel; COMBES, Hélène. El clientelismo político: desde 1950 hasta nuestros días. Buenos Aires: Siglo XXI Editores, 2016. 192 p. 